\title{
PROMOÇÃO DE SAÚDE BUCAL EM INDIVÍDUOS PORTADORES DE ALCOOLISMO CRÔNICO
}

Cassiano Lima CHAIBEN, Vanessa TORTADO, Liana Lins LUCHETTA, Max Falchetti COSSUL, Antonio Adilson Soares de LIMA

O alcoolismo constitui uma síndrome multifatorial com comprometimento físico e mental, além dos impactos sociais. Ele se destaca hoje como um dos mais graves problemas de saúde pública, devido às complicações sobrevindas no plano somático e psíquico, além de profunda repercussão no meio social. Os pacientes alcoólatras apresentam um risco elevado ao desenvolvimento de várias doenças bucais. O objetivo deste estudo é apresentar o perfil dos pacientes alcoólatras e sua condição bucal. Após a aprovação do Comitê de Ética em pesquisa (CEP/SD: 1007.132.10.09), foram examinados 98 pacientes internados em hospital para tratamento contra álcool e outras drogas. Os indivíduos foram submetidos a exame intrabucal sob o auxílio de luz artificial nas enfermarias. Todos os pacientes eram do sexo masculino e com média de idade de 38,8 anos. O consumo médio de etanol foi de 1,56 litros/dia. Em geral, os pacientes também faziam uso de cigarros industrializados ou usaram outras drogas ilícitas (crack, maconha e cocaína). As condições bucais mais freqüentemente diagnosticadas nestes pacientes foram: doença periodontal, cárie, língua saburrosa e a candidose bucal. O diagnóstico precoce, o tratamento e a prevenção destas entidades promovem uma melhoria na saúde e na qualidade de vida destes indivíduos.

Palavras chave: Etanol; Alcoolismo; Saúde Bucal; Relações DentistaPaciente. 